be substantially compliant with the risk-reduction components of the Standard. Nonetheless, full compliance with the Standard on schedule will require concerted effort in most institutions, and our readers are likely to shoulder a large portion of the responsibility for these efforts. It is imperative that the actual text of the Standard be obtained from the Federal Register or, once available, from OSHA. Clearly, though, further help will be needed. We will try to provide some guidance in the next quarterly SHEA Newsletter, but for further assistance, we all look to:

The local or regional office of the Federal OSHA (also, in those states that have established agencies to which OSHA has delegated its enforcement duties, the offices of such agencies).

The AHA. Useful materials include AHA's book on Universal Precautions and the recently telecast video conference on the
OSHA standard, which will be available soon on videocassette. Be sure your "front office" knows to copy relevant AHA announcements to you.

\title{
SHEA Annual Meeting Registration
}

You still have time to register for the SHEA Annual Scientific

Meeting, and if you register by February 28, 1992, you will qualify for the reduced "Early Bird" rate. So get to it! The meeting will be held April 12-14, 1992, in Baltimore, Maryland. If you need further information, call the SHEA Meetings Department at (609) 845-7220.

Brief items of interest for the SHEA N ews or Newsletter may be sent to Robert A. Weinstein, MD, SHEA, N ewsletter Editor, Division of Infectious Diseases, M ichael Reese Hospital, Lake Shore D rive at 31st St., Chicago, IL 60616; FAX (312) 791-3577. Copy must be typed, doublespaced, and may not exceed five pages. 